Silvana Krause' ${ }^{1}$, Bruno Marques Schaefer ${ }^{1}$ e Tiago Alexandre Leme Barbosa'

\title{
Dinâmicas de surgimento de novos partidos na América do Sul (1979-2015)
}

\section{Introdução}

O estudo de novos partidos, em novas ou consolidadas democracias (LUCARDIE, 2000; HUG, 2001; TAVITS 2006, 2008), iniciou-se no final da década de $1970^{2}$, a partir da desconstrução da tese de "congelamento" dos sistemas partidários europeus (HAUSS \& RAYSIDE, 1978), proposta por LIPSET e ROCKKAN (1967). A emergência destas novas organizações marcou um processo de estruturação de atores políticos a partir de demandas pós-materialistas (Partidos Verdes), da reatualização de discursos de extrema-direita (IGNAZI, 1996), da reordenação de elites já inseridas em novas siglas com vias a sobreviver politicamente, ou mesmo enquanto projetos pessoais de busca de poder (LUCARDIE, 2000). O sucesso de novos partidos em democracias consolidadas levantou questões importantes acerca da própria estabilidade dos sistemas partidários (KESTLER et al., 2013), gerando desafios às siglas já consolidadas (IGNAZI, 1995). O sucesso de novos competidores, no entanto, foi exceção e não regra (BOLLEYER e BYTZEK, 2016) e outro ponto importante investigado por esta literatura foi: quais

Universidade Federal do Rio Grande do Sul, Porto Alegre, RS, Brasil.

2 O trabalho de La Palombara e Weiner (1966), também merece ser ressaltado. Os autores, no entanto, propõem um modelo de análise que dá conta do surgimento dos sistemas partidários e não de novos partidos em sistemas partidários consolidados ou renovados.

3 Rochon (1985) vai mais longe e afirma que os sistemas partidários nunca estiveram congelados. Revista Brasileira de Ciência Política, no 27. Brasília, setembro - dezembro de 2018, pp 73-104. 
as variáveis mais propícias à consolidação ou efemeridade destas novas organizações? Como obtém sucesso ou fracassam?

O debate em relação às consequências da entrada de novos partidos em sistemas partidários é amplo e inconclusivo em termos normativos. Se, por um lado, alguns autores apontam que novos partidos podem ser um sinal de vitalidade do sistema partidário, com a inclusão de novas elites políticas (VAN COTT, 2003); de outro, há o risco de que a entrada de novos partidos pode instabilizar o regime democrático, principalmente se estes novos partidos surgem com tendências antissistêmicas (DINAS et al., 2016; IGNAZI, 1996). Em termos históricos, o fim de regimes militares e a consequente redemocratização tem sido um campo de estudo fértil para a análise do efeito de novos partidos no sistema, se sinal de vitalidade ou instabilidade do regime democrático em consolidação (MAINWARING, 1996; LINZ e STEPAN, 1999).

Neste trabalho, não entraremos na seara normativa, ou positiva, em termos de analisar se novos partidos tendem ter um papel de oxigenação do sistema político, ou podem ser sinal de sua decadência. Em outra direção, nos ocupamos de analisar as condições de surgimento de novos partidos em 10 países da América do Sul, durante o período de 1979 a 2015. Nosso objetivo é responder a questão: quais variáveis impactam na emergência de novos partidos na região? Para respondê-la, este artigo está organizado em quatro sessões: 1) a definição conceitual do que entendemos por novo partido; 2) o desenho metodológico da pesquisa; 3 ) a análise dos resultados e, por fim, 4) as considerações finais. É importante ressaltar que este trabalho consiste em um exercício exploratório, ou seja, visa testar hipóteses aventadas pela literatura que possam contribuir na agenda de pesquisas sobre novos partidos na região.

\section{Quadro de Análise}

Entendemos serem necessárias duas considerações antes da exposição do quadro de análise. Primeiramente, há que se diferenciar, historicamente, o surgimento do fenômeno partidário do surgimento 
de novos partidos. O primeiro ocorre, na Europa ${ }^{4}$, ao fim do século XIX e início do século XX, com a estruturação da competição política a partir do surgimento dos modernos partidos de massa (DUVERGER, 1992). O segundo ocorre, como destacamos anteriormente, a partir do "descongelamento" da competição partidária no continente europeu. No caso sul-americano, podemos apontar um primeiro momento de competição partidária que inicia ao fim do século XIX em alguns países (Uruguai, Argentina, Colômbia, Chile, Venezuela), ou na metade do século XX em outros (Brasil, Paraguai, Equador, Bolívia, Peru), e é interrompido por uma sucessão de golpes civil-militares (O’DONNELL, 1988), especialmente iniciados na década de 1960. Posteriormente, os processos de redemocratização fomentam um novo ciclo de competição partidária, com o surgimento de novos atores ${ }^{5}$, e a reativação de siglas mais antigas (Cavarozzi, 1988). A segunda consideração que deve ser levada em conta, na literatura sobre novos partidos, é a diferenciação da ideia de surgimento e sucesso. Voltaremos a essa questão mais adiante.

A agenda de pesquisas sobre novos partidos, em geral, possui distinções teóricas e metodológicas bastante claras. Existem estudos que consideram o surgimento de novas organizações a partir da representação de clivagens sociais e culturais, canalizadas em mecanismos institucionais específicos (LÓPEZ, 2005); ou enquanto produto da ação consciente de atores racionais que buscam maximizar ganhos e minimizar prejuízos (TAVITS, 2008).

Quanto a questões metodológicas também há distinções importantes. Alguns estudos se orientam em buscar regularidades e variações entre países (HARMEL e ROBERTSON, 1985), com o objetivo de medir os efeitos de variáveis específicas sobre a formação de novos partidos ${ }^{6}$. Outros estudos se centram em poucos casos (nova direita, nova esquerda) (DINAS et al, 2013); ou casos específicos

4 E pode-se considerar em outros contextos, como os EUA (Aldrich, 1995), e mesmo a América do Sul (Mainwaring e Scully, 1996).

5 Caso do Brasil, ver Mainwaring (1996).

6 Neste sentido, geralmente, a unidade de análise é a eleição. Busca-se medir a variação do surgimento de novos partidos a partir da variação de indicadores como: inflação, desemprego e mudanças institucionais. 
(VAN COTT, 2003), não com a intenção de identificar padrões, mas sim características específicas - estruturais, conjunturais e/ou institucionais - que possibilitam a emergência de novas organizações partidárias.

O trabalho de HAUSS e RAYSIDE (1978) foi um dos pioneiros na tentativa de sistematizar uma teoria que explicasse o surgimento de novos partidos. Os autores apresentam uma reflexão contrária a tese do "congelamento partidário" e propuseram um estudo comparado de 23 casos de novos partidos, ou proto-partidos, que emergiram nos EUA e na Europa Ocidental entre as décadas de 50 e 70. O modelo proposto consistia no teste de uma série de variáveis que poderiam explicar porque surgem novos partidos ou não. A investigação chega ao resultado de que duas condições seriam necessárias, mas não suficientes para que um partido surgisse: a existência de clivagens no interior da sociedade que poderiam ser mobilizadas politicamente (capital/trabalho; centro/periferia; igreja/ estado, questões étnicas); e facilitadores institucionais (representação proporcional, a existência de autonomia dos estados). Estes fatores só se manifestariam em novos partidos, no entanto, se, no contexto, houvesse variáveis eminentemente políticas e da ordem de ação dos atores: a existência de liderança que pudesse mobilizar o grupo partidário, o apoio de organizações externas (sindicatos, uniões estudantis, movimentos sociais), o comportamento dos partidos já consolidados quanto à possibilidade de emergência de novos atores e a possibilidade de resposta do eleitorado (quanto maior volatilidade, maior probabilidade de inserção de um novo competidor no mercado eleitoral). A concepção dos autores foi que as elites que tentam fundar os partidos analisam um conjunto de variáveis e, desta forma, agem com vias a conquistar seus objetivos. A baixa taxa de sucesso, e mesmo emergência, de novos partidos nos EUA, por exemplo, foi interpretada a partir da percepção das elites de que as variáveis políticas seriam insuficientes. $\mathrm{O}$ movimento por direitos civis, principalmente na década de 60 , não se constituiu em partido, apesar da existência de uma clivagem social latente. $\mathrm{O}$ comportamento dos partidos consolidados, em especial o 
Partido Democrata, foi de incluir as lideranças em seus quadros, o que "esvaziou" o projeto de uma nova organização partidária.

Esta estratégia de pesquisa foi seguida a partir de modelos que consideravam outras variáveis e outras metodologias. HARMEL e ROBERTSON (1985), analisaram, em conjunto, mais de 200 partidos que obtiveram registro na Europa Ocidental e EUA: a variável dependente considerada foi a variação entre os números de novos partidos surgidos a cada nova eleição, e as variáveis independentes foram de natureza social (taxa de desemprego, crescimento econômico, inflação), cultural e institucional (existência ou não de representação proporcional, existência ou alguma forma de subvenção pública para os partidos). HUG (2001) e, posteriormente, TAVITS (2006; 2008) seguiram passos semelhantes. Influenciado pela teoria dos jogos, o primeiro cunhou o conceito de "cálculo estratégico" como variável explicativa. Este consistiria, basicamente, no cálculo que as elites, em termos positivos, fariam antes de se engajar no processo de conquista do registro partidário. Tavits sintetiza o conceito em: “(...) o partido que entra na disputa, a sua recompensa é igual ao benefício de entrar no Gabinete (b), vezes a probabilidade de ser eleito (p), menos os custos de entrada" ${ }^{7}$ (TAVITS, 2006, p.102).

Esta escola de matriz quantitativa desenvolve-se concomitantemente com análises qualitativas que foram férteis, principalmente, no estudo de países em processo de redemocratização ou de democracias recentes. Como exemplo podemos citar o trabalho de Van COTT (2003), que propõe uma análise multicausual para entender o processo de emergência e sucesso de partidos indígenas na Bolívia, bem como LÓPEZ (2005), em sua análise sobre o surgimento de novos partidos de esquerda na América Latina, ainda na região, temos o trabalho de MUSTILLO (2007), que do surgimento de novos partidos de forma comparada. A emergência da extrema-direta europeia foi objeto de estudos de caso, como os trabalhos de IGNAZI (1996) e DINAS et al (2013).

7 "(...) the party enterers the contest, its payoff equals the benefict of holding Office (b), times the probability of getting elected (p), minus the costs of entry (c)" (Tradução Livre). 
No caso da América do Sul, os novos partidos, ou novos competidores fazem parte de uma incipiente literatura. No Brasil, a temática relativa a nova direita foi trabalhada por CODATO et al (2015), estudos de caso foram realizados por KRAUSE et al (2017), e mesmo na Colômbia com LOSADA \& LIENDO (2015), por exemplo. A despeito dessas importantes contribuições, a literatura ainda carece de pesquisas que estudem de forma comparada o surgimento de novas organizações na região.

O desafio parece residir na consideração da complexidade da realidade social e a consequente parcimônia das conclusões. $\mathrm{O}$ uso de modelos rígidos, geralmente importados (WEYLAND, 2002), desconsidera características específicas da realidade local, assim como os estudos de caso pecam pela perda de contexto geral (LANDMAN, 2008). Neste trabalho, buscamos utilizar análise estatística descritiva e multivariada, no intuito de realizar comparação entre variáveis e descrição dos casos.

Partindo das variáveis utilizadas pela literatura especializada, iremos testar as variáveis utilizadas para o caso em questão. Faz-se necessário também esclarecer o que será entendido como um "novo partido" neste estudo. Comparativistas destacam a importância do desenho da pesquisa comparativa em ao menos dois níveis: i) teórico e conceitual (SMELSER, 1968; SARTORI, 1970; COLLIER e MAHON Jr, 1993); e ii) o número de casos e unidade de análise (RAGIN, 1987; LANDMAN, 2008) ${ }^{8}$. Em relação ao primeiro ponto, estão as preocupações de se trabalhar com conceitos que não sejam enviesados culturalmente, e que sejam suficientemente amplos, em níveis mais elevados da "escala da abstração", segundo o trabalho de SARTORI (1970). No nosso caso, a definição sobre o que é um novo partido passa por outras questões, em especial, a quantidade de dimensões que formariam o conceito.

BARNEA e RAHAT (2011) revisam a literatura sobre a temática e identificam duas estratégias nos estudos. A primeira trabalha com uma definição mais "ampla", considerando como novo aqueles 
competidores que conquistam o registro definitivo, e somente esta dimensão. A segunda estratégia se vale de uma definição mais restrita, considerando mais de uma dimensão das agremiações: filiados, membros, parlamentares eleitos, por exemplo. A proposta dos autores é que se trabalhe com sete dimensões dos "novos" partidos ${ }^{9}$. O trabalho apresenta justificativas plausíveis para inserção dessas variáveis, o que significa um conceito mais restrito de novo partido. Mesmo que mais preciso, o problema em se trabalhar com essa definição se daria na coleta de dados. Uma comparação com esses critérios implicaria em um esforço mais intensivo em múltiplas fontes, que, geralmente, não se encontram disponíveis para o estudo dos partidos políticos (RIBEIRO, 2013) ${ }^{10}$.

Por conta das fontes disponíveis, optamos por utilizar uma definição ampla sobre o que é um "novo" partido. Assim define-se como novo, os competidores estreantes nas eleições para a Câmara Baixa, ou seja, as agremiações são contabilizadas como "novas" na medida em que lançam candidatos em uma determinada eleição. $\mathrm{O}$ conceito é suficientemente amplo para abarcar todos competidores estreantes, pois escolhe-se o critério da participação eleitoral ${ }^{11}$. Esta escolha possibilita comparações ao nível agregado, favorecendo a identificação de padrões ${ }^{12}$, que podem ser testados qualitativamente, em estudos de caso.

Antes de prosseguir para a definição do modelo de análise, ressaltamos a diferenciação exposta anteriormente, entre a ideia de surgimento e sucesso dos novos partidos. HARMEL e ROBERTSON (1985), por exemplo, operacionalizam estas diferenças a partir de duas variáveis dependentes: o surgimento é, tão somente, a obtenção

9 É importante ressaltar que mesmo advogando uma definição mais precisa, os autores não aplicam o conceito comparativamente e nem trabalham com um $n$ grande. Os autores se valem de apenas um caso, e, curiosamente, não aplicam todas as dimensões advogadas no texto.

10 No próprio trabalho de Barnea e Rahat (2011), os autores somente testam três das sete dimensões propostas conceitualmente, em apenas um caso.

11 O que vai ao encontro da definição sartoriana: "Um partido é qualquer grupo político identificado por um rótulo oficial que apresente em eleições, e seja capaz de colocar através de eleições (livres ou não), candidatos a cargos públicos" (Sartori, 1982, p.192)

12 Trabalhamos com todos os partidos que participaram de eleições na série temporal proposta, no entanto, nos testes consideramos somente aqueles que conquistaram uma cadeira no Parlamento. 
de registro e a competição eleitoral (nem que seja em somente uma eleição), e o sucesso seria a obtenção, na eleição de entrada da organização, de mais de cinco por cento dos votos. Outros autores utilizam critérios distintos para determinar o que seria o sucesso, tais como: conquista da presidência (KESTLER et al, 2013), ou sobrevivência ao longo do tempo (ROSE e MACKIE, 1983). Este ponto é importante, afinal de contas, por vezes pode-se superestimar o número de novos partidos surgidos em dada eleição, sem considerar a relevância destas agremiações. Neste trabalho, utilizamos o critério de HARMEL e ROBERTSON (1985), considerando o percentual de $5 \%$ no debut eleitoral.

\section{Desenho da Pesquisa}

Partimos dos dados de eleições realizadas em dez países da América do Sul, durante o período de 1979 a 2015. A escolha se justifica por duas razões: a ainda fraca presença de estudos comparados sobre partidos na região, em larga escala ( $\mathrm{Su}, 2013)$, e porque os países da América do Sul possuem semelhantes histórias políticas (KESTLER et al, 2013), com uma tendência há interrupções autoritárias e uma cultura política pouco afeita aos partidos (ALCÁNTARA e SAEZ, 2002) ${ }^{13}$. A escolha do período se justifica, pois, o mesmo é suficiente largo para abranger os processos de transição política nos dez países, até o período atual. Os dados foram extraídos de diversas fontes, desde secundárias, como os trabalhos de NOHLEN (2005), SU (2013), e CAMPELLO (2015), até bases de dados disponíveis na internet, como: o Political Database of the Americas (PBDA) ${ }^{14}$, o acervo de dados eleitorais de Adam Carr ${ }^{15}$, indicadores disponíveis

\footnotetext{
13 Isso não quer dizer, de forma alguma, que consideremos os partidos na região como muito distintos de seus congêneres de outros espaços geográficos. A desconfiança em relação aos partidos, como apontam estudos recentes (MANIN, 2013), não é uma exclusividade sul americana.

14 GEORGETOWN UNIVERSITY. Political Parties. Disponível em: http://pdba.georgetown.edu/. Acessado em 25 de junho de 2017.

15 CARR, Adam. Psephos. Disponível em: http://psephos.adam-carr.net/. Acessado em 26 de junho de 2017.
} 
nos sítios eletrônicos da Cepal ${ }^{16}$, Banco Mundial ${ }^{17}$ e do IDEA $^{18}$. Os dados foram sistematizados no SPSS (Software Package Social Sciences), para realização dos testes específicos ${ }^{19}$.

Em um primeiro momento realizamos uma análise estatística descritiva, em que nosso objetivo era observar todos os países em nível agregado. Posteriormente, passamos à análise multivariada. Buscamos investigar se existiam diferenças no número de partidos surgidos em dada eleição controlando este resultado por uma série de variáveis independentes. Neste sentido, consideramos duas variáveis dependentes $(\mathrm{Y})$ : o número absoluto de novos partidos surgido em uma eleição, e o número destes novos partidos que alcançaram, no mínimo, cinco por cento dos votos. A justificativa deste número de corte está inspirada no trabalho de Harmel e Robertson (1985), e considera que os novos partidos que alcançaram mais de cinco por cento dos votos, para a Câmara Baixa, em seu debut eleitoral são partidos que surgem mais fortes e com tendência a permanecer no sistema. As variáveis independentes $(\mathrm{X})$ são de natureza institucional (sistema eleitoral, possibilidade de partidos regionais competirem nacionalmente, número de assinaturas necessárias para o registro do partido em termos proporcionais a população nacional, eleições presidenciais coincidentes), conjuntural (eleição pós-regime militar), e social (crescimento do PIB, desemprego, participação eleitoral e anos de democracia). Estas variáveis são organizadas em termos de hipóteses como colocado abaixo:

H1 (Instituições): As regras que regulam a competição eleitoral e o registro dos partidos impactam na emergência de novas organizações (TAVITS, 2006).

Instituições mais permissivas podem constituir incentivos a elites que visam fundar um partido. Neste sentido, países com registro

16 NAÇÕES UNIDAS - COMISSÃO ECONÔMICA PARA AMÉRICA LATINA E O CARIBE. Dados e estatísticas. Disponível em: http://www.cepal.org/pt-br/datos-y-estadisticas. Acessado em 24 de junho de 2017.

17 WORLD BANK GROUP. World Bank Open Data. Disponível em: http://data.worldbank.org/. Acessado em 23 de junho de 2017

18 INTERNATIONAL INSTITUTE FOR DEMOCRACY AND ELECTORAL ASSITANCE. Voter Turnout Database. Disponível em: http://www.idea.int/. Acessado em 22 de junho de 2017.

19 O N final foi de 91 casos. 
partidário permissivo (pouco ou nenhum número de assinaturas necessário), são, por hipótese, mais favoráveis a novos atores (SU 2013). As outras variáveis do modelo também indicam permissibilidade, na medida em que nos países onde existe a possibilidade de um partido regional competir nas eleições nacionais (Argentina), os custos de entrada são menores. Além de que o sistema eleitoral para a Câmara dos Deputados (ou Cámara Baja), sendo proporcional e não majoritário (Brasil, Colômbia, Uruguai, Peru e Argentina) ${ }^{20}$, em tese, engendra mais possibilidades de que um novo partido ganhe uma cadeira no Legislativo. Também consideramos que quando existem eleições conjuntas para a Presidência e a Câmara Baixa, existe maior probabilidade de surgirem novos partidos, tanto aqueles que visam a vitória para o Executivo, quanto aqueles que visam alcançar o máximo de representação legislativa que possibilite barganhas futuras com a coalizão presidencial (Borges, 2015).

H2 (Conjuntura): Adicionamos a variável Eleição pós-Regime Militar como uma variável conjuntural que impacta na emergência de novas organizações. O raciocínio se fundamenta na expectativa de que com o final do Regime Militar a primeira eleição constituiria uma oportunidade para novos atores se organizarem e competirem eleitoralmente ${ }^{21}$.

H3 (Fatores Sociais): Seguindo a literatura temática (Harmel e Robertson, 1985), pontuamos que baixo crescimento econômico e alto desemprego ${ }^{22}$ são incentivos a novos atores, principalmente "desafiadores". Períodos de crise são "janelas de oportunidades". Assim como os demais indicadores ilustrariam sistemas partidários não consolidados, e/ou abertos. Baixa participação eleitoral e, mesmo, poucos anos de democracia. No "cálculo" das elites, principalmente

20 O financiamento público foi excluído da análise, por que somente dois países dos dez não o adotam.

21 Para esta variável, em nossa amostra, os casos colombiano e venezuelano foram excluídos. Afinal de contas, os dois países passaram por transições políticas na década de 70 e 80.

22 Primeiramente coletamos os dados de todas as variáveis concernentes a hipótese nas fontes anteriormente citadas. A natureza de tais variáveis é contínua. Para realização dos testes propostos, transformamos cada variável em dicotômica, fazendo a divisão a partir da mediana de cada país de nossa amostra. Apesar de critério arbitrário, é método utilizado, e recomendado, em outros trabalhos científicos (SANDELOWSKI, 2000). 
considerando partidos de tipo pessoais (LUCARDIE, 2000), a pouca preocupação da população com a competição eleitoral seria um incentivo a entrada no sistema, ou, no caso de "cisões" partidárias, a saída de elites de um partido com vias a fundar outro não seria prejudicada. Na próxima sessão, apresentamos os resultados.

\section{Análise de Resultados}

Dividindo a nossa amostra por décadas e considerando a média e o desvio padrão das variáveis dependentes, podemos observar que há uma tendência geral de diminuição do aparecimento de novas legendas partidárias. Na década de 80, por exemplo, foram realizadas 23 eleições legislativas nos dez países analisados. Em média, surgiram 8,74 partidos em cada uma dessas, com grandes variações. Enquanto no Uruguai, em 1984, apenas um novo partido obtém registro e compete eleitoralmente, no Equador, no mesmo ano, surgem cinco novos partidos. O desvio padrão capta esta variação entre eleições e países. Quando consideramos, no entanto, a segunda variável dependente, os números se alteram, mas a tendência se mantém. Na mesma década, em média, surgiu somente um partido que alcançou mais de cinco por cento dos votos em disputa. Este número indica que os sistemas, de modo geral, são permissivos no que concerne a entrada de novos atores, mas são mais fechados no que concerne o sucesso destas organizações. Observando novamente os casos de Uruguai e Equador, em 1984, enquanto o único partido surgido no caso uruguaio não alcançou votação expressiva, no caso equatoriano, três dos cinco partidos passaram a "barreira" dos cinco por cento dos votos (PRE, DP/UDC e PD) $)^{23}$.

23 Respectivamente, Partido Roldosista Ecuatoriano, Democracia Popular-Unión Demócrata Cristiana e Partido Demócrata. 
Tabela 1: Número de novos partidos surgidos na América do Sul (1979-2015)

\begin{tabular}{|c|c|c|c|c|c|}
\hline & & $\begin{array}{l}\text { Número de Eleições } \\
\text { Realizadas }\end{array}$ & & $\begin{array}{l}\text { Número de } \\
\text { Partidos }\end{array}$ & $\begin{array}{l}\text { Número de partidos } \\
\text { com mais de } 5 \%\end{array}$ \\
\hline \multirow[t]{8}{*}{ Série Temporal } & Anos 1980 & 23 & Média & 8,74 & 1,13 \\
\hline & & & Desvio Padrão & 10,58 & 1,22 \\
\hline & Anos 1990 & 29 & Média & 6,00 & 0,76 \\
\hline & & & Desvio Padrão & 8,89 & 0,95 \\
\hline & Anos 2000 & 24 & Média & 3,71 & 0,96 \\
\hline & & & Desvio Padrão & 3,92 & 1,46 \\
\hline & Anos 2010 & 15 & Média & 2,73 & 0,60 \\
\hline & & & Desvio Padrão & 2,49 & 1,06 \\
\hline
\end{tabular}

Fonte: elaboração dos autores ${ }^{24}$.

Apresentamos, na Tabela 2, os dados descritivos a partir dos países, controlando as médias também por região. Distinguimos cinco países como sendo do Cone Sul, incluindo o Paraguai, e cinco países como Andinos. A divisão é arbitraria e se justifica tão somente como um recurso ilustrativo. Podemos observar que os países ao sul do subcontinente têm, em média, um número menor de novos partidos, sendo os casos de Chile, Paraguai e Uruguai os mais extremos. Nestes países, os sistemas partidários se apresentaram como os mais "fechados" à entrada de novos atores políticos. Chile e Uruguai mantiveram a estrutura de seus sistemas partidários com a redemocratização (MAINWARING e SCULLY, 1996), mantendo a estabilidade da competição. Enquanto no Paraguai, entre regimes militares, o que se registrou foi a manutenção da hegemonia do Partido Colorado e suas mutações nominais (atualmente ANR) ${ }^{25}$, ao longo de quase todo o período analisado $^{26}$. Argentina e Brasil tiveram sistemas mais permeáveis a novos atores, no entanto, sem que estes acabassem conquistando votações expressivas em suas respectivas estreias eleitorais. Nos dois casos, foi exceção o sucesso de novas organizações no período analisado, sendo que na Argentina a disputa presidencial foi realizada, ao longo de

24 Considere-se as fontes apresentadas na sessão anterior.

25 Asociación Nacional Republicana.

26 A ANR perde a eleição em 2008 para o partido-movimento Alianza Patriótica para el Cambio (APC), organizada em torno da candidatura presidencial de Fernando Lugo. 
quase todo o período, entre a UCR (Unión Cívica Radical) e o PJ (Partido Justicialista), partidos com raízes históricas. Houve somente eventual apresentação de terceiras forças, como a FREPASO (Frente País Solidário), e mais recentemente o PRO (Propuesta Republicana). Este último, inclusive, apresenta-se eleitoralmente pela primeira vez em 2005 e acaba conquistando a presidência dez anos depois, com Maurício Macri (VOMMARO e GENÉ, 2017). No caso brasileiro, o sistema partidário, apesar das críticas quanto a sua baixa institucionalização (MAINWARING, 1996), acabou por manter um padrão de competição restringido aos grandes partidos, principalmente aqueles surgidos na década de 80 .

Tabela 2: Média de novos partidos surgidos na América do Sul, por país (1979-2015)

\begin{tabular}{ccccc}
\hline Região & País & $\begin{array}{c}\text { Número de Novos } \\
\text { Partidos }\end{array}$ & $\begin{array}{c}\text { Número de Novos } \\
\text { Partidos, mais de 5\% }\end{array}$ & Diferenças \\
\hline ConeSul & Argentina & 4,69 & 0,31 & 4,38 \\
& Brasil & 5,56 & 0,78 & 4,78 \\
& Chile & 2,57 & 0,43 & 2,14 \\
& Paraguai & 1,83 & 0,83 & 1,00 \\
& Uruguai & 1,43 & 0,14 & 1,29 \\
\hline Andinos & Bolívia & 5,11 & 1,78 & 3,33 \\
& Colômbia & 10,9 & 0,60 & 10,3 \\
& Equador & 3,00 & 1,15 & 1,85 \\
& Peru & 7,17 & 2,50 & 12,13 \\
\hline & Venezuela & 13,00 & 0,88 & 4,59 \\
\hline
\end{tabular}

Fonte: elaboração dos autores

Quanto aos casos dos países chamados aqui "Andinos", a média foi consideravelmente maior, no número de novos partidos surgidos e na entrada destes enquanto competidores efetivos. Colômbia e Venezuela foram os países em que mais surgiram novas organizações, sem, no entanto, que estas obtivessem sucesso expressivo. Nas eleições colombianas de 1998, por exemplo, 42 novos partidos, e movimentos políticos, se apresentaram eleitoralmente 
pela primeira vez. Nenhum destes, no entanto, alcançou os cinco por cento dos votos. O caso peruano, neste quesito, é o que merece maior destaque. No país, em média, surgiram sete partidos por eleição, sendo que quase três destes ultrapassaram a barreira de porcentagem. Na eleição de 1990, por exemplo, seis novos partidos estreiam eleitoralmente, sendo que três acabam por conquistar mais de cinco por cento dos votos (FREDEMO, C90 e IS) ${ }^{27}$.

É importante notar que embora os países analisados possuam histórias políticas em comum (KESTLER et al, 2013), alguns aspectos dos seus sistemas partidários e mesmo das suas instituições políticas variam. Assim, um olhar mais atento sobre esses países revela aspectos interessantes sobre os casos em si. Dentro das diferenças encontradas, podemos destacar, por exemplo, as próprias tradições dos sistemas partidários das regiões. O Brasil, por exemplo, é reconhecidamente um caso que além de contar com um dos sistemas partidários mais fragmentados do mundo (MAINWARING, 2001) possui distintas lógicas regionais, dado o formato federativo do estado brasileiro (LIMA Jr, 1983). O país também se diferencia dos demais pelo fato de ter permitido a existência de eleições durante o período militar, diferentemente dos demais regimes militares da região.

Ao contrário do caso do Brasil, temos os casos de Uruguai e Chile. Países que não somente são territorialmente menores ${ }^{28}$, mas também possuem sistemas partidários mais estáveis, variando entre dois e três partidos. No Uruguai, por exemplo, o sistema partidário do país tem se estruturado em termos de dois ou três partidos, conforme BUQUET \& PIÑEIRO (2014), já o Chile possui uma competição estável entre dois blocos ideológicos, alternando-se no poder presidencial. A Argentina, com a permissão constitucional de que partidos regionais compitam em nível nacional para a Câmara Baixa, apresenta, como o Brasil, uma oscilação no número de novos partidos surgidos ao longo do período analisado.

No gráfico 1, destacamos os dados de surgimento dos novos partidos no Cone Sul e Paraguai. Cada linha se refere à soma de novos partidos surgidos em cada país ao longo das décadas trabalhadas no

27 Respectivamente: Frente Democrático, Cambio 90 e Izquierda Socialista.

28 Alguns estudos colocam o tamanho do país e da população como uma variável para explicar o surgimento de novos (Bolin, 2014) 
artigo. Podemos observar duas tendências: crescimento do número de novos partidos após período de estabilização do sistema partidário (Brasil e Uruguai na década iniciada em 2010), e decréscimo do número de novos partidos (Chile, Argentina e Paraguai, na mesma década). Os casos brasileiro e uruguaio são interessantes. Eles demonstram dinâmicas inversas, apesar de seus perfis de origens serem semelhantes na medida em que os novos partidos nestes países são cisões de elites políticas de agremiações já existentes. Enquanto no Brasil a maioria dos novos partidos é fruto de um reordenamento de elites em busca de se aproximar da base do então governo Dilma (PT) (KRAUSE et al, 2017), no Uruguai o movimento foi de oposição. Ou seja, no primeiro caso os parlamentares de centro-direita buscaram se aproximar de um governo de esquerda, do outro militantes anteriormente vinculados ao partido de esquerda Frente Amplio buscaram ir mais ao extremo do campo ${ }^{29}$.

Gráfico 1: Novos partidos surgidos no Cone Sul

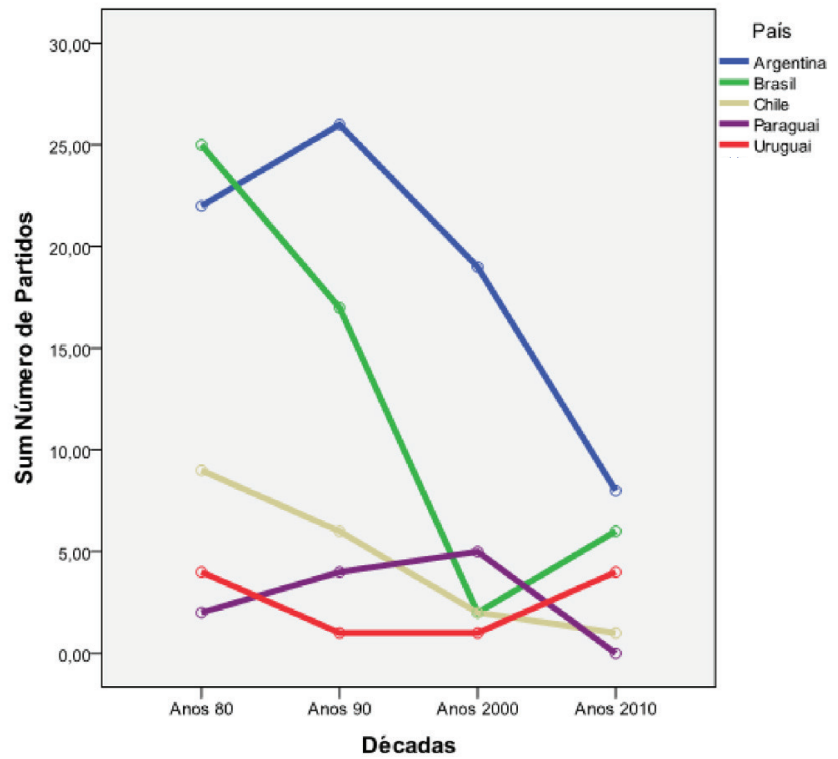

Fonte: elaboração dos autores 
No gráfico 2, observamos que a tendência de aumento de novos partidos, quando observada a competitividade das novas agremiações em seu debut eleitoral, é distinta. Apenas no caso brasileiro surgiu um partido novo com mais de $5 \%$ dos votos na década iniciada em 2010. Nos demais países parece ter havido uma acomodação do sistema partidário, sendo que a entrada de novos atores políticos relevantes - conforme nossos critérios - esteve "bloqueada".

Gráfico 2: Novos partidos surgidos no Cone Sul (mais de $5 \%$ dos votos)

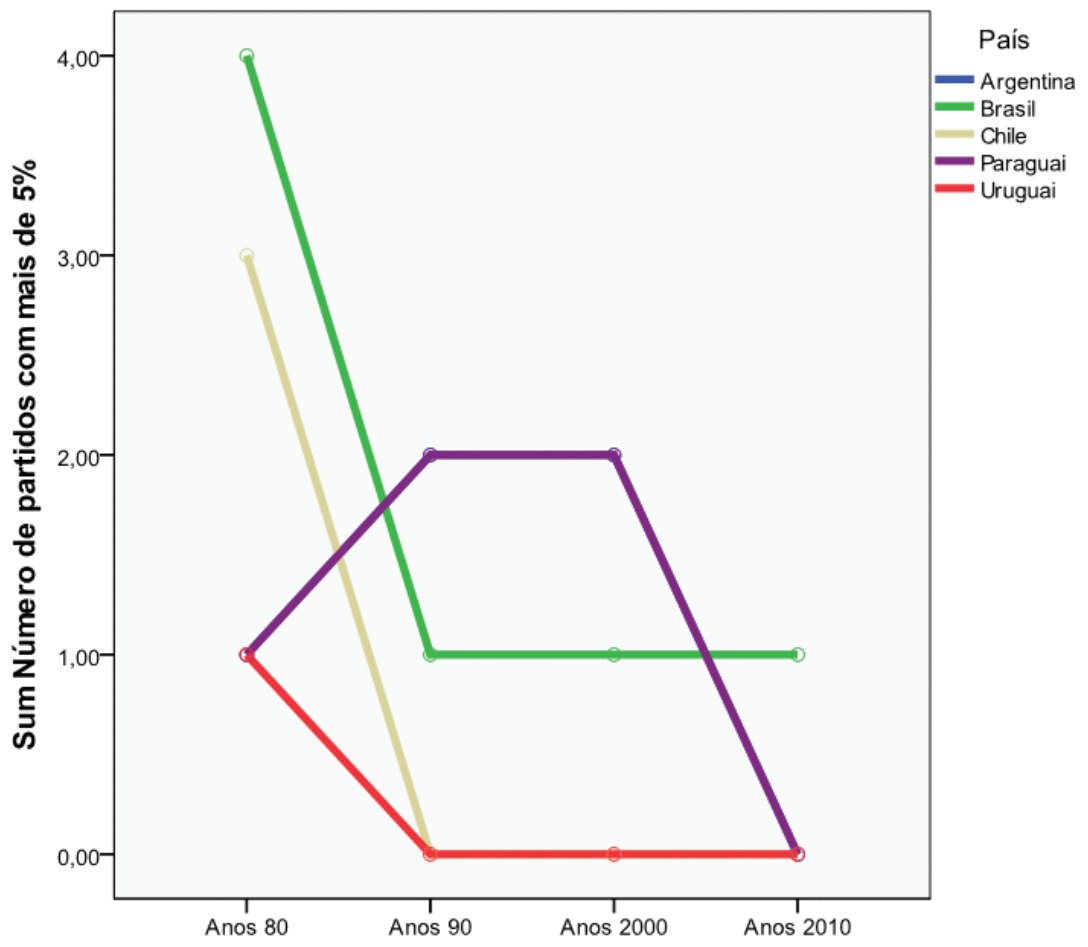

Décadas

Fonte: elaboração dos autores.

Os dados do gráfico 3 especificam os resultados dos assim chamados países Andinos, temos dois casos que destoam dos demais. Venezuela registra as maiores taxas de surgimento de 
agremiações, o primeiro país conhece o auge na década de 1980, dez anos depois, taxas semelhantes seriam encontradas na Colômbia. Esses dois casos se diferenciam pelas histórias políticas específicas, no entanto, a mesma estabilização no número de novos competidores pode ser fruto das mudanças distintas, mas que tiveram o semelhante efeito. A chegada de Hugo Chávez na presidência da República, no caso venezuelano, e na Colômbia, as mudanças nas regras eleitorais LOSADA \& LIENDO (2015), podem explicar a diminuição no número de novos partidos.

Gráfico 3- Número de novos partidos por país (1980-2010)

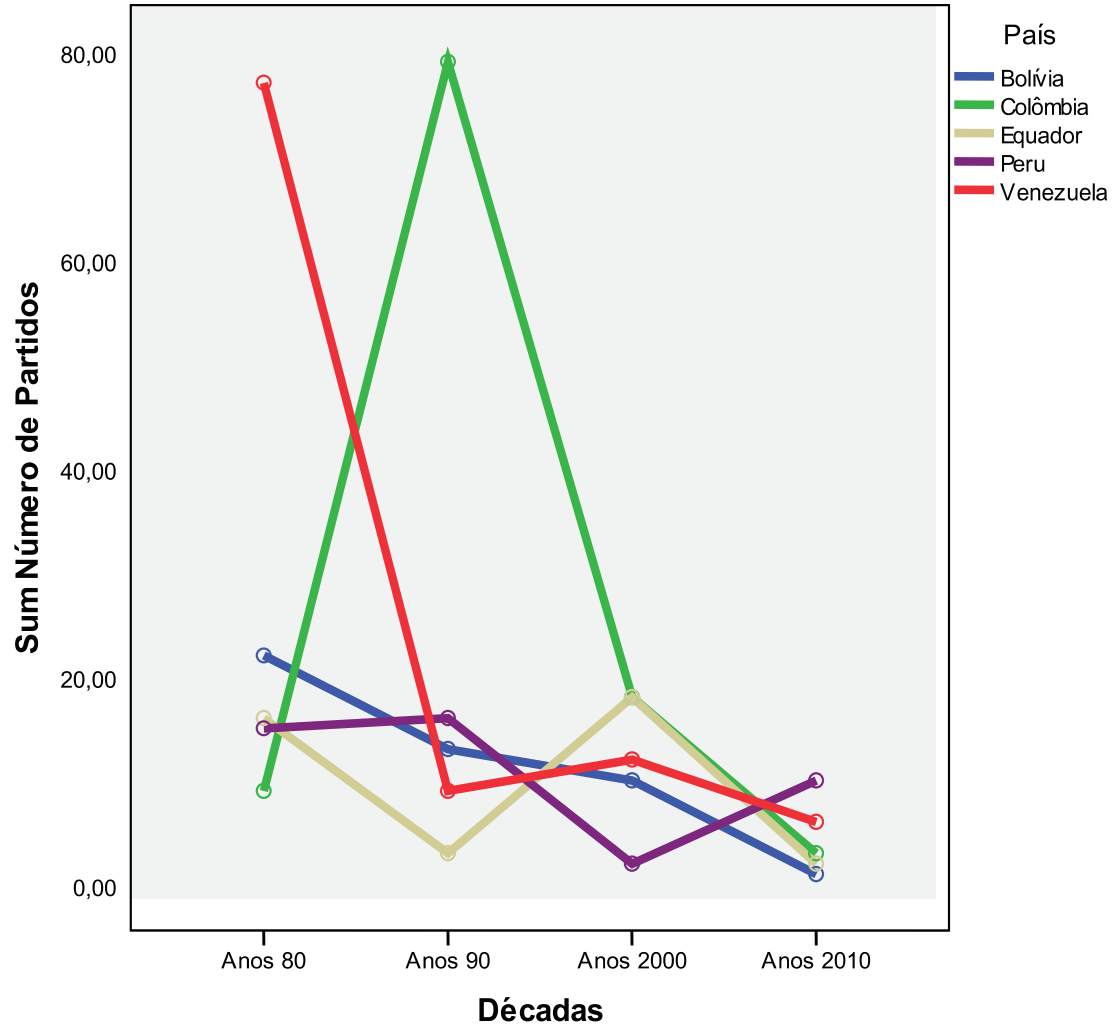

Fonte: elaboração dos autores. 
Gráfico 4 - Partidos surgidos que obtém ao menos 5\% dos votos na primeira eleição

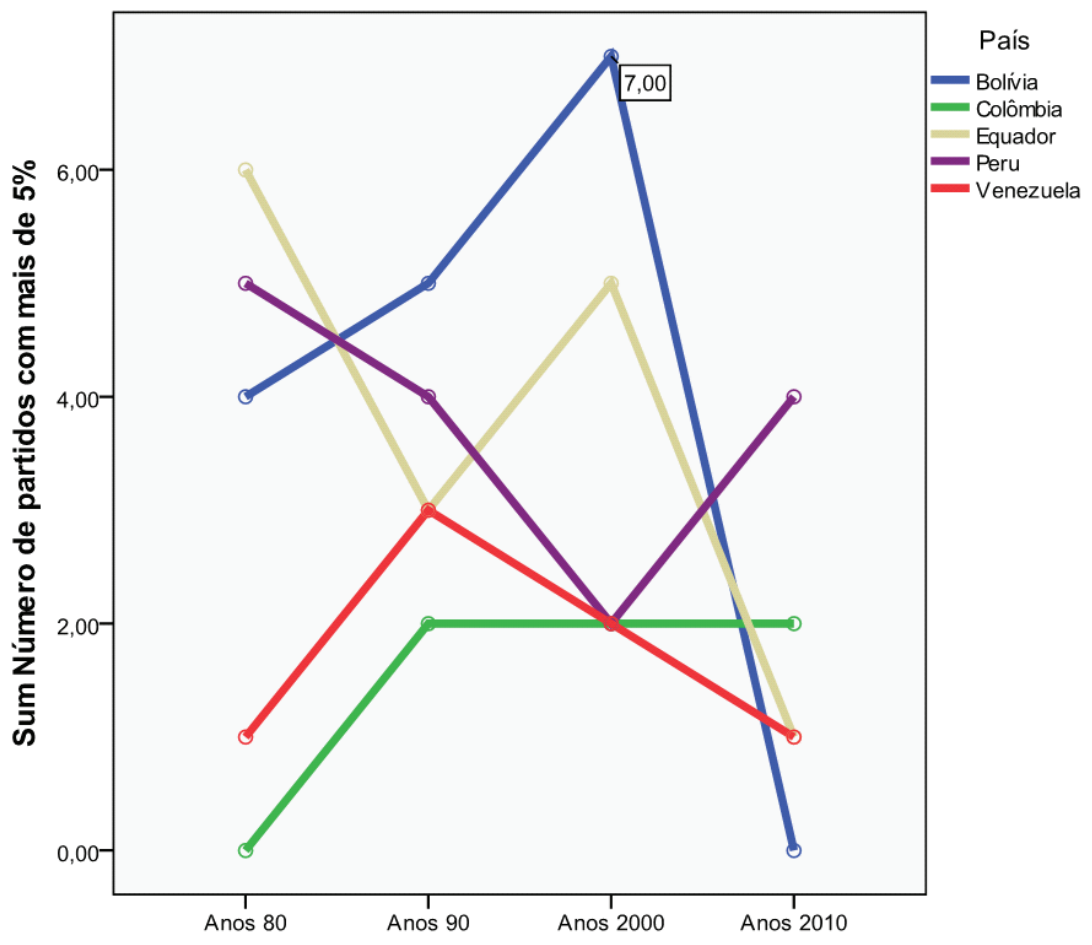

Décadas

Fonte: elaboração dos autores.

O que explica o surgimento de novos partidos na América do Sul?

Partimos, agora, para o teste das hipóteses enunciadas na sessão anterior. Passamos, em outras palavras, de uma avaliação comparativa de casos, para uma análise que leve em conta as variáveis a serem testadas. Considerando as variáveis dependentes de maneira contínua, existem diferenças significativas de médias, tendo em vista as variáveis independentes. Na tabela 3 expomos os dados. Calculamos a diferença de médias a partir do teste T. Ou seja, considerando as variáveis independentes como dicotômicas, observamos o comportamento das variáveis dependentes quando as primeiras acontecem (1) e quando não acontecem (0). No primeiro caso, 
quando o sistema eleitoral do país é proporcional e não misto, ou majoritário, a tendência é que surjam mais de seis novos partidos por eleição. Enquanto menos de um, conseguiu alcançar cinco por cento dos votos. As diferenças expostas nas duas últimas colunas confirmam, e negam, as hipóteses anteriormente enunciadas. Em caso de o número ser positivo a hipótese é confirmada, e quando negativo o contrário. Quanto ao sistema eleitoral, por exemplo, considerando o surgimento de novos partidos (valor absoluto), a hipótese é confirmada: a representação proporcional possibilita maior entrada de novos atores, no entanto não tem o mesmo efeito quando consideramos como variável dependente o sucesso destes novos partidos. O número de assinaturas necessárias para obtenção do registro, crescimento do PIB no ano anterior a eleição e anos de democracia, são variáveis que têm o comportamento esperado. Apesar de confirmarem nossas hipóteses quanto à entrada de novos atores, têm efeitos contrários quando considerado o número de novos partidos que obtém sucesso em sua estreia eleitoral.

Outra informação que merece destaque é que o nível de significância varia muito. No caso do número total de novos partidos, sistema eleitoral, número de assinaturas e anos de democracia são significantes (ao nível de 5\%), enquanto as demais variáveis não apresentam diferenças significativas. No caso da segunda variável dependente, a eleição pós-abertura é a que apresenta maior nível de significância. Ou seja, quando finda o regime militar e a primeira eleição é realizada novos partidos surgem e obtém sucesso eleitoral. 


\section{Tabela 330: Diferença de Médias em relação ao surgimento de novos partidos}

\begin{tabular}{|c|c|c|c|c|c|c|}
\hline Variáveis (X) & & Variáveis & $\begin{array}{c}\text { Número } \\
\text { de } \\
\text { Partidos }\end{array}$ & $\begin{array}{c}\text { Número de } \\
\text { partidos com } \\
\text { mais de } 5 \% \\
\text { dos votos }\end{array}$ & $\begin{array}{l}\text { Diferenças no } \\
\text { número de } \\
\text { novos partidos }\end{array}$ & $\begin{array}{l}\text { Diferenças no } \\
\text { número de } \\
\text { novos partidos } \\
\text { com Sucesso }\end{array}$ \\
\hline \multirow[t]{8}{*}{ Instituiç̧ões } & Sistema Eleitoral & Misto & 3,52 & 1,00 & 2,80 & $-0,17$ \\
\hline & & $\mathrm{RP}$ & 6,32 & 0,83 & & \\
\hline & Partidos Regionais & Não & 5,26 & 0,76 & 0,49 & 0,20 \\
\hline & & Sim & 5,75 & 0,96 & & \\
\hline & Assinaturas & $\begin{array}{c}\text { Mais } \\
\text { assinaturas }\end{array}$ & 3,68 & 1,07 & 5,32 & $-0,54$ \\
\hline & & $\begin{array}{c}\text { Menos } \\
\text { assinaturas }\end{array}$ & 9,00 & 0,53 & & \\
\hline & Eleição Presidencial & Não & 6,12 & 0,59 & $-0,70$ & 0,36 \\
\hline & & Sim & 5,42 & 0,95 & & \\
\hline \multirow[t]{2}{*}{ Conjunturais } & Eleição Pós-Abertura & Não & 5,29 & 0,76 & 1,78 & 0,86 \\
\hline & & Sim & 7,08 & 1,62 & & \\
\hline
\end{tabular}

30 O teste Té um teste que visa aceitar ou rejeitar a hipótese nula. No caso de um grau de significância maior do 0,05, a hipótese nula é aceita, ou seja, não há relação estatística esperada. No nosso caso, os resultados são os seguintes, para todas as variáveis. Sistema Eleitoral (Se proporcional ou misto): Significância número de novos partidos: 0,044; Significância número de novos partidos com mais de 5\% de votos na primeira eleição: 0,579. Partidos Regionais (possibilidade de existência ou não): Significância número de novos partidos: 0,339; Significância número de novos partidos com mais de $5 \%$ de votos na primeira eleição: 0,393. Número de assinaturas (Alto ou baixo): Significância número de novos partidos: 0,001; Significância número de novos partidos com mais de $5 \%$ de votos na primeira eleição: 0,019. Eleição presidencial (Sim ou não): Significância número de novos partidos: 0,637; Significância número de novos partidos com mais de 5\% de votos na primeira eleição: 0,275. Eleição pós-abertura democrática (Sim ou não): Significância número de novos partidos: 0,698; Significância número de novos partidos com mais de 5\% de votos na primeira eleição: 0,185. Crescimento do PIB (Alto ou baixo): Significância número de novos partidos: 0,062; Significância número de novos partidos com mais de 5\% de votos na primeira eleição: 0,664. Desemprego (Alto ou baixo): Significância número de novos partidos: 0,221; Significância número de novos partidos com mais de 5\% de votos na primeira eleição: 0,757. Participação eleitoral (Sim ou não): Significância número de novos partidos: 0,504; Significância número de novos partidos com mais de $5 \%$ de votos na primeira eleição: 0,264. Anos de democracia (Mais anos ou menos): Significância número de novos partidos: 0,024; Significância número de novos partidos com mais de $5 \%$ de votos na primeira eleição: 0,802. 


\begin{tabular}{|c|c|c|c|c|c|c|}
\hline \multirow[t]{8}{*}{ Estruturais } & PIB & $\begin{array}{c}\text { Baixo } \\
\text { Crescimento }\end{array}$ & 4,20 & 0,91 & 2,67 & $-0,06$ \\
\hline & & $\begin{array}{c}\text { Alto } \\
\text { Crescimento }\end{array}$ & 6,87 & 0,85 & & \\
\hline & Desemprego & $\begin{array}{c}\text { Baixo } \\
\text { Desemprego }\end{array}$ & 4,85 & 0,83 & 1,42 & 0,11 \\
\hline & & $\begin{array}{c}\text { Alto } \\
\text { Desemprego }\end{array}$ & 6,27 & 0,93 & & \\
\hline & Participação Eleitoral & $\begin{array}{c}\text { Alta } \\
\text { Participação }\end{array}$ & 5,24 & 1,00 & 0,71 & $-0,22$ \\
\hline & & $\begin{array}{c}\text { Baixa } \\
\text { Participação }\end{array}$ & 5,96 & 0,78 & & \\
\hline & Democracia Anos & $\begin{array}{l}\text { Mais anos de } \\
\text { democracia }\end{array}$ & 4,32 & 0,91 & 2,38 & $-0,06$ \\
\hline & & $\begin{array}{l}\text { Menos anos } \\
\text { de democracia }\end{array}$ & 6,70 & 0,85 & & \\
\hline Total & & Total & 5,55 & 0,88 & & \\
\hline
\end{tabular}

Fonte: elaboração dos autores.

O teste $\mathrm{T}$, apesar de importante, apenas ilustra distinções dentro da amostra, considerando as variáveis. Para avançarmos na análise, propomos um modelo de regressão logística, transformando as variáveis dependentes de contínuas para dicotômicas. Logo, quando surge um novo partido consideramos como 1 e quando não 0 (Modelo 1). O mesmo vale para a questão do sucesso (Modelo 2). Outra questão que deve ser dita é que, no teste $T$, transformamos variáveis independentes contínuas em dicotômicas, considerando as medianas. Observamos, por exemplo, os dados referentes ao crescimento do PIB de dado país, calculamos a mediana e classificamos na amostra os valores de 0 (Baixo Desemprego) e 1 (Alto Desemprego). Nossa hipótese, confirmada parcialmente, é que com alto desemprego a probabilidade de surgirem novas organizações é maior. Com o modelo de regressão, podemos manter a variável em sua natureza "originária", ou seja, contínua. Logo, podemos captar nuances da 
análise que não seriam possíveis quando a mesma foi considerada dicotômica. Os resultados são apresentados na tabela 4.

A primeira informação importante é sobre o nível de significância. No modelo 1, apenas uma variável foi significante, qual seja: a possibilidade de partidos regionais competirem nacionalmente (valor p: 0,05). Os dados exponenciais de beta indicam que quando há essa possibilidade, existem mais seis chances de que um novo partido surja. A representação proporcional e o número de assinaturas (em termos proporcionais), além de não apresentarem significância estatística, possuem valores contrários às hipóteses. Ou seja, apesar de explicarem as diferenças de médias da variável dependente, quando contínua, não explicam a mesma quando dicotômica.

Tabela 4: Modelo Logístico31

\begin{tabular}{|c|c|c|c|c|c|c|c|}
\hline & & \multicolumn{3}{|c|}{$\begin{array}{c}\text { Modelo } 1 \\
\text { Variável Dependente - Surge } \\
\text { ou não novo partido }\end{array}$} & \multicolumn{3}{|c|}{$\begin{array}{c}\text { Modelo } 2 \\
\text { Variável Dependente - Surge } \\
\text { ou não novo partido - 5\% }\end{array}$} \\
\hline & & B & Sig. & $\operatorname{Exp}(B)$ & B & Sig. & $\operatorname{Exp}(B)$ \\
\hline \multirow[t]{4}{*}{ Instituições } & $\mathrm{RP}$ &,- 650 & ,437 &, 522 & ,293 & ,615 & 1,341 \\
\hline & Partidos Regionais & 1,798 & ,050 & 6,036 &,- 403 &, 488 & 668 \\
\hline & Assinaturas &,- 520 & ,441 &, 594 & 1,334 & ,009 & 3,795 \\
\hline & Eleição Presidencial & 1,071 & ,253 & 2,918 &,- 072 & ,916 & ,930 \\
\hline Conjuntura & Eleição Pós-Abertura & & & & 2,171 & ,017 & 8,766 \\
\hline \multirow[t]{4}{*}{ Estrutura } & PIB &, 029 & ,724 & 1,030 & ,019 & ,748 & 1,019 \\
\hline & Desemprego & 027 &, 814 & 1,027 & ,151 &, 064 & 1,163 \\
\hline & Participação Eleitoral &, 018 &, 503 & 1,018 & ,001 & ,955 & 1,001 \\
\hline & Anos de Democracia &, 039 &, 273 & 1,040 &,- 010 & ,650 & 990 \\
\hline
\end{tabular}

Fonte: elaboração dos autores.

No caso do Modelo 2, são duas as variáveis que possuem significância estatística: o número percentual de assinaturas e a eleição

31 Os resíduos de Cox-Snell são um tipo de resíduos padronizados usados em análises de confiabilidade. Um resíduo é a diferença entre um ponto de dados observado e um valor predito ou ajustado. No modelo 1 o resultado do teste de Cox e Snell foi de 0,276. No modelo 2, o resultado foi de 0,112. 
pós-abertura. A primeira, neste caso, possui o efeito contrário ao esperado: quanto mais assinaturas são necessárias para o registro partidário, maior a probabilidade de que ao menos um novo partido surja com representatividade eleitoral. Este fato corrobora os dados de TAVITS $(2006 ; 2008)$. Segundo a autora, um número percentual elevado de assinaturas desencoraja novos partidos de surgirem, a não ser que estes possuam já estruturas organizativas que possibilitem o colhimento das mesmas. Estas estruturas organizativas são refletidas, então, no processo eleitoral. A conjuntura possui, também, um efeito significativo e positivo. Num contexto de abertura, novos partidos tendem a surgir com relevância eleitoral (em mais de oito vezes), o que parece valer tanto para sistemas partidários em que as velhas organizações retornam depois do fim do regime, caso chileno, ou que o sistema partidário é completamente novo, caso brasileiro. No primeiro, em 1989, ano da primeira eleição pós-Pinochet, competem PPD (Partido por la Democracia), UDI (Unión Demócrata Independiente), e RN (Renovación Nacional). Os três partidos surgem antes do pleito, mas competem pela primeira vez na eleição de abertura. No caso do segundo, consideramos a eleição legislativa de abertura como a de 1982, em que competem com maior expressividade eleitoral o PMDB (Partido do Movimento Democrático Brasileiro), PDS (Partido Democrático Social) e PDT (Partido Democrático Trabalhista). Os três obtêm registro anteriormente, mas sua primeira eleição para a Câmara se dá naquele ano. É importante observar também que duas variáveis, apesar de não significativas, possuem resultados distintos ao esperado. $\mathrm{O}$ caso de partidos regionais competirem nacionalmente e os anos de democracia apontam no caminho inverso.

\section{Considerações Finais}

Os resultados deste trabalho apontam que variáveis institucionais, conjunturais e sociais impactam na emergência de novas organizações partidárias na América do Sul, no período de 1979 a 2015. Isto é reforçado, sobretudo, quando analisamos o número absoluto de novos partidos surgidos. Quando alteramos a variável dependente 
com um ponto de corte, considerando os novos partidos que, em seu debut eleitoral, já são relevantes, as variáveis com maior impacto se alteram, especialmente se observarmos a questão do registro partidário: número de assinaturas necessárias para a conquista do mesmo. Este fato corrobora teses levantadas sobre outros contextos regionais, como já demonstrado por TAVITS (2006; 2008). Além disso, podemos observar determinadas tendências em termos de tempo e espaço. Ao passar dos anos, há estabilização da competição partidária em muitos países e o padrão geral foi o decréscimo da entrada de novos atores. Comparando os dados referentes à primeira década estudada (anos 80), com a última (anos 2010), observamos que, ao nível agregado, existem diferenças significativas. Quanto a questões de espaço, em países como Chile e Uruguai, os sistemas partidários estiveram fechados à entrada de novos atores ao longo de quase todo o período, enquanto na Colômbia e Venezuela houve oscilações maiores. Nestes dois países, a emergência de novas organizações não foi acompanhada pelo sucesso das mesmas, dado que poucas alcançaram alguma relevância e muitas outras competiram em somente um pleito.

Quando alteramos a variável dependente de sua natureza contínua para dicotômica, pudemos observar mudanças significativas no efeito de determinadas variáveis. A possibilidade de partidos regionais competirem eleitoralmente, por exemplo, foi significativa para a entrada de novos competidores, mas não para o sucesso dos mesmos. Os partidos podem surgir em dada província, disputar eleições, mas por competirem em um limitado espaço geográfico não possuem tendência de chegar a um estado de relevância nacional, possuem pouca margem para isso. Para o sucesso, parece importante que o novo competidor já possua uma estrutura organizativa, ou se aproveite de conjunturas muito específicas (LUCARDIE, 2000), tais como uma eleição inaugural pós-Regime Militar.

Apontamos também para a complementaridade necessária entre métodos quantitativos e qualitativos, principalmente para a explicação de casos em que as condições são semelhantes e os resultados 
distintos. A compreensão do fenômeno de surgimento de novos partidos demanda a utilização de múltiplas estratégias, tal como já apontado pelo trabalho de VAN COTT (2003). Como afirma RAGIN (1987, p.19) um dos "folclores" das ciências sociais consiste na afirmação de que os fenômenos sociais são "complexos" ${ }^{32}$. O fato dos fenômenos serem multicausais não implica na ausência de explicação. A inclusão de novas variáveis e o deslocamento do olhar, neste sentido, da estrutura para os agentes, parecem ser questões imprescindíveis para o avanço da agenda de pesquisas sobre novos partidos, em geral, e na América do Sul, em particular.

\section{Referências Bibliográficas:}

ALCÁNTARA SAÉZ, Manuel \& FREIDENBERG, Flavia (2002). "Partidos Políticos na América Latina". Opinião Pública, Vol. 8, $\mathrm{n}^{\circ} 2$, p. 137-157.

ALDRICH, John H (1995). Why Parties? The Origin and Transformation of Political Parties in America. Chicago: University of Chicago Press.

BARNEA, Shlomit \& RAHAT, Gideon (2011). "Out with the old, in with the 'new': What constitutes a new party?" Party Politics, Vol. $17, \mathrm{n}^{\circ} 2$, p. 303-320.

BOLLEYER, Nicole \& BYTZEK, Evelyn (2016). "New party performance after breakthrough: Party origin, building and leadership". Party Politics, Vol. 23, n 6, pp. 772-782.

BORGES, André (2015). "Nacionalização Partidária e Estratégias Eleitorais no Presidencialismo de Coalizão". Dados, Vol. 58, nº 3, pp. 651-688.

BUQUET, Daniel; \& PIÑEIRO, Rafael (2014). La Consolidación de un Nuevo Sistema de Partidos en Uruguay. Revista Debates, V.8, N.1, pp.127-148.

32 "Yet this depiction of social life does not fit well with experience. We sense that there is a great deal of order to social phenomena- that there is method to the madness" (Ragin, 1987 p. 19) 
CAMPELLO, Daniela (2015). “Institucionalização Partidária e Consistência Programática: A Resposta da Esquerda a Ataques Especulativos na América Latina”. Dados, Vol. 58, nº. 2, p. 427-460.

CARR, Adam. Psephos. Disponível em: http://psephos.adam-carr. net/. Acessado em 26 de junho de 2017.

CAVAROZZI, Marcelo (1988). “Ciclos políticos na Argentina a partir de 1955”, em O’DONNEL, Guillermo; SCHMITTER, Philippe C. \& WHITEHEAD, Laurence. Transições de Regime Autoritário: América Latina. São Paulo: Editora Vértice.

CODATO, Adriano; BOLOGNESI, Bruno; ROEDER, Karolina Mattos (2015). A nova direita brasileira: uma análise da dinâmica partidária e eleitoral do campo conservador. In: Sebastião Velasco e Cruz; André Kaysel; Gustavo Codas. (Org.). Direita, volver! O retorno da direita e o ciclo político brasileiro. 1ed. São Paulo: Editora Fundação Perseu Abramo, pp. 115-143.

COLLIER, David e MAHON JR, James (1993). “'Stretching' Revisited: Adapting Categories in Comparative Analysis Source". The American Political Science Review, Vol. 87, nº 4, pp. 845-855. DINAS, Elias; GEORGIADOU, Vassiliki, KONSTANTINIDIS, Iannis \& RORI, Lamprini (2013). "From dusk to dawn: local party organisation and party success of right-wing extremism". Party Politics, Vol. 22, no 1, pp. 80-92.

DUVERGER, Maurice (1992). Los Partidos Políticos. Cidade do México: Fondo de Cultura Económica.

GEORGETOWN UNIVERSITY. Political Parties. Disponível em: http://pdba.georgetown.edu/. Acessado em 25 de junho de 2017. HARMEL, Robert \& ROBERTSON, John. D. (1985). "Formation and Success of New Parties: A Cross-National Analysis". International Political Science Review, Vol. 6, no 4, pp. 501-523.

HAUSS, Charles \& RAYSIDE, David (1978). "The development of new parties in western democracies since 1945”, in COOPER, Joseph \& MAISEL, Louis. Political Parties: development and decay. Beverly Hills: Sage. 
HUG, Simon (2001). Altering Party Systems: Strategic Behavior and the Emergence of New Political Parties in Western Democracies. Ann Arbor: University of Michigan Press.

IGNAZI, Piero (1996). "The Crises of Parties and the Rise of New Political Parties”. Party Politics. Vol. 2, nº4, pp. 549-566.

(1995). "The Re-emergence of the Extreme Right in Europe”. Reihe Politikwissenschaft, no 21, pp. 1-15.

INTERNATIONAL INSTITUTE FOR DEMOCRACY AND ELECTORAL ASSITANCE. Voter Turnout Database. Disponível em: http://www.idea.int/. Acessado em 22 de junho de 2017.

KESTLER, Thomas; KRAUSE, Silvana \& LUCCA, Juan B (2013). "Los Break-in parties en América Latina: ¿éxito o fracaso?". Revista Debates, Vol. 7, n 2, pp. 159-171.

KIRCHHEIMER, Otto (1972). "The Transformation of the Western European Party", em LA PALOMBARA, Joseph \& WEINER, Myron. Political Parties and political Development. Princeton/ Nova Jersey: Princeton University Press, pp. 137-176.

KRAUSE, Silvana; GERARDI, Dirceu André; SCHAEFER, Bruno Marques (2017). "As coligações do novo PSD: da máquina aos grotões, da métrica aos resultados., em KRAUSE, Silvana; MACHADO, Carlos; MIGUEL, Luis Felipe. Coligações e Disputas eleitorais na Nova República. Aportes téorico-metodológicos, tendências e estudos de caso. Rio de Janeiro. São Paulo. Ed. Fundação Konrad Adenauer e UNESP.

LANDMANN, Todd (2008). Issues and methods in comparative politics: an introduction. Londres/Nova Iorque: Routledge.

LA PALOMBARA, Joseph \& WEINER, Myron (1966). “The Origin and Development of Political Parties", in LA PALOMBARA, Joseph \& WEINER, Myron. Political Parties and political Development. Princeton/Nova Jersey: Princeton University Press, pp. 3-42.

LIMA J., Olavo Brasil. Partidos Políticos brasileiros: a experiência regional e federal 1945-64. Rio de Janeiro: Graal. 
LINZ, Juan J. \& STEPAN, Alfred (1999). “A transição e consolidação da democracia: a experiência do sul da Europa e da América do Sul”. São Paulo: Paz e Terra.

LIPSET, Seymour M.\&ROKKAN, Stein(1967). “CleavageStructures, Party Systems, and Voter Alignments: An introduction", em LIPSET, Seymour M. \& ROKKAN, Stein. Party Systems and Voter Alignements: Cross National Perspectives. Londres/Nova Iorque: The Free Press Macmillan Limited.

LÓPEZ, Santiago (2005). "Partidos desafiantes en América Latina: representación política y estrategias de competencia de las nuevas oposiciones". Revista de Ciencia Política (Santiago), Vol. 25, no 2, pp. 37-64.

LOSADA, Rodrigo \& LIENDO, Nicolás (2015). El peso de los Nuevos Partidos en el sistema de partidos colombiano, 19862010. Pap.polit. vol.20, n.1, pp.35-62.

LUCARDIE, Paul (2000). "Prophets, Purifiers and Prolocutors: Towards a Theory on the Emergence of New Parties". Party Politics, Vol.6, n² 2, pp.175-185.

MAINWARING, Scott (1996). “Brasil. Partidos Débiles, Democracia Indolente", em MAINWARING, Scott \& SCULLY, Timothy. La Construcción de Instituciones Democráticas: Sistema de Partidos en América Latina. Santiago: CIEPLAN.

MAINWARING, Scott \& SCULLY, Timothy (1996). "Introducción: Sistemas de Partidos en la América Latina", em MAINWARING, Scott \& SCULLY, Timothy. La Construcción de Instituciones Democráticas: Sistema de Partidos en América Latina. Santiago: CIEPLAN.

MANIN, Bernard (2013). "A democracia do público reconsiderada”. Novos estudos CEBRAP, São Paulo, no 97, pp. 115-127.

MUSSTILLO, Thomas J .(2007). Entrants in the political arena: new party trajectories during the third wave of democracy in Latin America. A dissertation submitted to the faculty of the University of North Carolina at Chapel Hill in partial fulfillment of the requirements for the degree of Doctor of Philosophy in the, Department of Political Science. Chapel Hill. 
NAÇÕES UNIDAS - COMISSÃO ECONÔMICA PARA AMÉRICA LATINA E O CARIBE. Dados e estatísticas. Disponível em: http://www.cepal.org/pt-br/datos-y-estadisticas. Acessado em 24 de junho de 2017.

NOHLEN, Dieter (2005). Elections in the Americas. Volume II. South America. Oxford: Oxford University Press.

O'DONNEL, Guillermo (1988). "Introdução aos casos latinoamericanos”, em O'DONNEL, Guillermo; SCHMITTER, Philippe C. \& WHITEHEAD, Laurence. Transições do Regime Autoritário: América Latina. São Paulo: Editora Vértice.

PARANHOS, Ranulfo et al (2016). "Uma introdução aos métodos mistos”. Sociologias, Porto Alegre, Vol. 18, n 42, pp. 384-411.

PERES, Paulo S. (2009). "Revisitando a 'Teoria Geral' dos Partidos Políticos de Maurice Duverger”. Revista Brasileira de Informação Bibliográfica em Ciências Sociais, n 68, pp. 17-58.

(2005). "O Problema da Instabilidade Eleitoral na Europa: Uma Análise do Debate Teórico, Empírico e Metodológico". Revista Brasileira de Informação Bibliográfica em Ciências Sociais - BIB/Anpocs, n 60, pp. 87-117.

RAGIN, Charles C (1987). The comparative method: moving beyond qualitative and quantitative strategies. Los Angeles: University of California Press.

RAGIN, Charles C. \& RIHOUX, Benoît (2009). Configurational Comparative Methods: Qualitative Comparative Analysis (QCA) and Related Techniques. Londres: SAGE.

RAGIN, Charles C. \& ZARET, David (1983). "Theory and Method in Comparative Research: Two Strategies". Social Forces, Vol. 61, $n^{\circ}$. 3, pp. 731-754.

REMMER, Karen L (2008). “The Politics of Institutional Change: Reform in Latin America, 1978-2002". Party Politics, Vol. 14, nº 1, pp. 5-30.

RIBEIRO, Pedro F. (2013). "Organização e poder nos partidos brasileiros: uma análise dos estatutos”. Revista Brasileira de Ciência Política, no 10, pp. 225-265. 
ROCHON, Thomas (1985). Mobilizers and Challengers: Toward a Theory of New Party Success', International Political Science Review, 6: pp. 419-439.

ROSE, R. and MACKIE, T.T. (1988). 'Do Parties Persist or Fail? The Big Trade-off Facing Organizations, in: LAWSON, K. and MERKL, P. (eds.) When Parties Fails. Princeton University Press pp. 533-558.

SANDELOWSKI, M. (2000). Focus on Research Methods Combining Qualitative and Quantitative Sampling, Data Collection, and Analysis Techniques in Mixed-Method Studies. Research in Nursing \& Health. 23, pp.246-255. John Wiley \& Sons.

SARTORI, Giovanni (1970). "Concept misformation in comparative politics”. American Political Science Review, Vol. 64, no 4, pp. $1033-1053$.

Brasília: Editora UNB.

SMELSER, Neil (1968). "Notes on the Methodology of Comparative analysis of economic activity", em UNESCO. The Social Science: problems and orientations. Paris: Unesco.

SU, Yen-Pin (2013). "Party registration rules and party systems in Latin America". Party Politics, Vol. 21, n 2, pp. 295-308.

TAVITS, Margit (2008). "Party Systems in the Making: The Emergence and Success of New Parties in New Democracies." British Journal of Political Science, Vol. 38, n 1, pp. 113-133. (2006). "Party Systems Change: Testing a New Model of New Party Entry”. Party Politics. Vol.12, n 1, pp. 99-119. VAN COTT, Donna L (2003). "From Exclusion to Inclusion. Bolivia's 2002 Elections". Journal of Latin America Studies, Vol. 35, no 4, pp. 751-755.

VOMMARO, Gabriel \& GENÉ, Mariana (2017). “Argentina: el año de Cambiemos". Revista Ciencia Política, Vol. 37, n 2, pp. 231-253. 
WEYLAND, Kurt (2002). "Limitations of Rational Choice Institutionalism for the study of Latin American politics". Studies in Comparative International Development, Vol. 37, Issue 1, pp. 57-85.

WILLEY, Joseph (1998). "Institutional Arrangements and the success of new parties in old democracies". Political Studies, $\mathrm{n}^{\circ}$ 46, pp. 651-668.

WORLD BANK GROUP. World Bank Open Data. Disponível em: http://data.worldbank.org/. Acessado em 23 de junho de 2017.

\section{Resumo}

O início da década de 1980 caracteriza-se pelo esgotamento dos regimes autoritários na América do Sul. O longo processo de transição que passaram alguns países, ou a abrupta ruptura institucional de outros, marcou o retorno dos partidos à arena de disputa política. Como diversos autores pontuaram, desde então, tem-se assistido a emergência de novos atores políticos ou transformações de partidos anteriormente consolidados. Neste trabalho, investigamos as dinâmicas do surgimento de novos partidos no subcontinente. Os mesmos são tratados enquanto organizações que se apresentam pela primeira vez em pleito nacional. Consideramos todas as eleições (91) realizadas no período de 1979 até 2015, no sentido de observar as variações do número de novos partidos que surgiram em cada pleito, a partir de fontes secundárias (outros trabalhos) e primárias (bancos de dados dos respectivos tribunais eleitorais). A literatura que trata do surgimento de novos partidos, em democracias consolidadas ou emergentes, aponta distintas variáveis que impactam nos incentivos à gênese de novas organizações. Crises políticas ou sociais, atores políticos e/ou incentivos institucionais. Em nosso caso, a partir da análise estatística multivariada, buscamos perceber quais são as variáveis que têm mais efeito sobre o surgimento de novos partidos. Os resultados apontam que existem diferenças significativas entre os países, sendo os Andinos muito mais propensos à emergência de novos partidos, devido a alterações Constitucionais específicas. Causas sociais, como alto desemprego e baixo crescimento econômico, também foram significantes para explicar por que em alguns contextos surgiram mais novos partidos do que em outros.

Palavras-chave: Novos Partidos; América do Sul; Comparação; Eleições. 


\section{Abstract:}

The opening of the 1980s was characterized by the exhaustion of authoritarian regimes in South America. The long transition process that some countries have undergone, or the abrupt institutional rupture of others countries, marked the return of the parties to political arena. Thenceforth, as several authors have pointed out, there has been the emergence of new political actors or transformations of previously consolidated political parties. In this work, we investigate the dynamics of the emergence of new parties in the subcontinent. We thought these parties as organizations that participated for the first time in general elections. We take account of the general elections (91) carried out in the period from 1979 to 2015 through secondary (scholar's works) and primary sources (databases of the respective courts elections), observing the variations in the number of new parties that arose in each election. The literature concerned with the emergence of new parties in consolidated or emerging democracies points out different variables that influence in the genesis of new organizations, as political or social crises, political actors and / or institutional incentives. In our case, through multivariate statistical analysis, we seek to understand which are the variables that have the greatest impact on the emergence of new parties. The outcomes indicate that there are significant differences between countries, with Andean countries being much more prone to the emergence of new parties due to specific constitutional changes. Social causes, such as high unemployment and low economic growth, were also significant in explaining why in some contexts appeared more new parties than in others.

Keywords: New Political Parties; South America; Comparison; Elections.

Recebido em: 09 de março de 2018

Aprovado em: 20 de dezembro de 2018 